\title{
SOBRE A LEGITIMIDADE DA DESCRIÇÃO DE UMA IMAGEM DE MUNDO
}

\author{
About the legitimacy of a world- \\ picture description
}

\section{Diogo de França Gurgel}

Doutorando do Programa de Pós-Graduação em Filosofia da Universidade Fluminense do Rio de Janeiro (UFRJ), Bolsista CNPq, Rio de janeiro, RJ - Brasil, e-mail: diogo.gurgel@ gmail.com

\section{Resumo}

Neste texto, procurarei demonstrar a inadequação da crítica feita por Elizabeth Wolgast, em seu artigo "Se a certeza é uma forma de vida", aos últimos escritos de Wittgenstein denominados Sobre a Certeza. Contrariando a ideia apresentada por essa autora de que o filósofo teria entrado em contradição com sua própria concepção de significado ao estabelecer e explorar uma distinção entre proposições gramaticais e proposições empíricas, trabalho com a hipótese de que os argumentos apresentados em obras como as Investigações Filosóficas e Sobre a Certeza são complementares na elucidação da gramática da linguagem ordinária.

Palavras-chave: Imagem. Proposição. Uso. 


\section{Abstract}

In this paper, I deal with an inaccuracy in Elizabeth Wolgast's criticism of Wittgenstein's last writing On Certainty. In her article "Whether certainty is a form of life", Wolgast advances the thesis that Wittgenstein contradicts his former assumptions on the nature of meaning when he puts forward and develops the distinction between grammatical and empirical propositions. Opposing her view, I argue that the arguments presented in the Philosophical Investigations and those found in On Certainty work together to elucidate the grammar of common language.

Keywords: Image. Proposition. Use.

\section{INTRODUÇÃO}

Em pesquisas anteriores, cheguei à conclusão de que a tarefa de elucidação do significado de palavras concernentes ao nosso vocabulário psicológico, conforme apresentada nas Investigações Filosóficas, só encontra um desenvolvimento satisfatório se levarmos em conta certos argumentos só inteiramente desenvolvidos no Sobre a Certeza. Palavras típicas de nosso vocabulário psicológico, tais como "consciência", têm a explicação de seu uso significativo dificultada se tivermos em vista unicamente argumentos fundados no que tendo a chamar de argumento do aprendizado da linguagem por adestramento (Abrichten) - amplamente desenvolvido por Wittgenstein no Brown Book e nas Investigações. Procurando encontrar uma solução no próprio pensamento de Wittgenstein, antes de assumir precipitadamente uma falha em seus argumentos, deparei-me com a hipótese de que a ideia de uma imagem de mundo (Weltbild) compartilhada passível de descrição e a distinção entre regras indubitáveis e regras dubitáveis eram as peças que falavam para a resolução do problema. Não cabe aqui demorar-me muito na exposição detalhada do caminho percorrido, de modo que devo dizer unicamente que procurei demonstrar que proposições cujo estatuto me parecia misterioso, tais como "eu tenho consciência" e "todo falante tem consciência", podem ter seu sentido elucidado a partir da definição de proposições gramaticais, i.e., proposições que descrevem a estrutura ou a "rocha dura" (hartem Gestein) dos jogos de linguagem dentro de uma comunidade linguística. 
A possibilidade de nos valermos do mesmo recurso para, por exemplo, investigarmos gramaticalmente proposições dos campos da Ética e da Estética, pode parecer promissora. Uma pesquisa com esse direcionamento deveria se perguntar pela existência de proposições gramaticais que expressem possíveis atribuições de valor estabelecidas em nossa imagem de mundo (Weltbild). Entretanto, se quisermos prezar pelo rigor que sempre marca os estudos filosóficos, não podemos nos furtar a aplicar a tradicional questão wittgensteineana, a saber, "como é possível o aprendizado e o uso significativo da expressão x?", para as próprias proposições gramaticais de que fala o filósofo. Não podemos conceder de bom grado a legitimidade de um conceito sobre o qual há tão lacônicas considerações. A proposta de meu artigo é que se ponha a teste toda a concepção da existência de uma imagem de mundo passível de ser descrita por proposições gramaticais. Para auxiliar nesta tarefa, apresento algumas severas críticas feitas por Elizabeth Wolgast, em seu artigo "Se a certeza é uma forma de vida", às posições assumidas por Wittgenstein no Sobre a Certeza.

\section{Uma sumária consideração acerca do Sobre a Certeza}

Uma tese central no Sobre a Certeza, e que me parece realmente faltar como ideia explícita ou consolidada nas Investigações Filosóficas, é a tese de que as "regras constitutivas"1 de um jogo de linguagem podem ser expressas na forma de sentenças de caráter mitológico ou indubitável (WITTGENSTEIN, 1972, § 95 e $\S 102$ ) - ainda que muita delas sejam aprendidas na própria práxis e, muitas vezes, sem um estabelecimento formal (WITTGENSTEIN, 1972, § 95 e WITTGENSTEIN, 1979, § 54 e $\S 83$ ). Wittgenstein, do modo como compreendo, evidencia um uso da linguagem distinto dos usos expressivo e descritivo trabalhados mais enfaticamente nas Investigações. Ele fala de um uso da linguagem que descreveria não fatos e sim o "sistema de conviç̧ões" (WITTGENSTEIN, 1979, § 102) que comporia uma imagem de mundo comum a muitos jogos de linguagem dentro de uma comunidade linguística:

1 Adoto a terminologia de Michael Kober (1996, p. 424), no texto "Certainties of a worldpicture: the epistemological investigations of On Certainty". 
As proposições que descrevem essa imagem de mundo podem ser parte de um tipo de mitologia. E seu papel é como o das regras de um jogo; e o jogo pode ser aprendido de modo puramente prático, sem o aprendizado de nenhuma regra explícita (WITTGENSTEIN, $1972, \S 95)$.

Wittgenstein dá a entender que a filosofia termina por formular pseudo-questões ao confundir sentenças descritivas e sentenças que expressam convicções. Em algumas passagens de sua obra, o filósofo parece sugerir que essas sentenças que expressam convicções podem ser denominadas "proposições gramaticais" (por exemplo: (WITTGENSTEIN, 1972, § 58; WITTGENSTEIN, 1979, § 251). É a possibilidade de enunciar, na forma de proposições gramaticais, as convicções - as regras constitutivas do próprio jogo em que se está inserido - que confunde os filósofos (como G. E. Moore), levando-os a querer elucidar e procurar o valor de verdade de proposições que têm o caráter de pressuposto para que as descrições de fatos e a asserção do valor de verdade dessas descrições seja possível, i.e., para que possamos estabelecer definições, hipóteses, conclusões, em suma, enunciados sujeitos à dúvida e à correção.

\section{Apresentação da crítica de Elizabeth Wolgast}

Elizabeth Wolgast, em seu artigo "Se a certeza é uma forma de vida", procura expor uma contradição entre esse argumento apresentado no Sobre a Certeza, a saber, de que os usos correntes da linguagem se apoiam em um sistema de convicções passível de ser descrito por proposições gramaticais, e a concepção de significado apresentada nas Investigações Filosóficas, a saber, de que o significado de uma palavra é seu uso (WITTGENSTEIN, 1979, § 43). Segundo ela, a preocupação de Wittgenstein em acomodar os truísmos de Moore no corpo de seus argumentos acerca da natureza do significado é a raiz do problema que passo a apresentar.

O ponto central da crítica de Wolgast é a defesa de que o conferimento de um estatuto de indubitabilidade a certas proposições não implica numa demonstração de seu uso efetivo (ou significativo) na linguagem ordinária. Como assume o próprio Wittgenstein, proposições gramaticais como "Aqui está uma mão" ou "A Terra existe há muito tempo" seriam formas de expressão linguística que, em geral, não se constituem como lances em um jogo de linguagem, não exprimem nenhum 
conhecimento. No entanto, afirma o filósofo, todas as nossas proposições que exprimem conhecimento se apoiam nos pressupostos descritos em proposições gramaticais passíveis de serem compostas quando fazemos Filosofia. Em geral, pode-se dizer que Wolgast não nega que a identificação e enunciação de evidências podem ser fruto de uma atividade filosófica, entretanto, ela não reconhece que o uso ordinário da linguagem dependa do que é enunciado por proposições gramaticais.

Antes de enveredarmos por um estudo detalhado dos argumentos de Wolgast, é preciso explicar algo sobre a terminologia adotada por essa autora. Wolgast faz uma distinção entre "certeza controversa" (struggling certainty) e "certeza confortável" (comfortable certainty) a partir da seção 357 do Sobre a Certeza. Proposições como "Eu estou certo de que ele vem", a princípio, diferir-se-iam de truísmos como "A Terra existe há muito tempo" pelo fato de que não é difícil imaginarmos situações em que as primeiras podem ser postas em questão. Perguntas como "Como você sabe?" e "Você não pode estar se confundindo?" fariam sentido em contextos em que a proposição "Eu estou certo de que ele vem" é usada, mas o mesmo não se pode afirmar da segunda. Visto isso, passemos a uma análise dos três argumentos em que divido a crítica:

1) Como garantir que o que parece ser uma proposição indubitável para mim o é para todos? Wolgast se utiliza de passagens da própria obra de Wittgenstein para evidenciar a problematicidade deste ponto: "Por que não há dúvidas de que eu me chamo L. W.? Isso realmente não parece algo que alguém possa estabelecer de uma vez por todas como estando acima de qualquer dúvida. Alguém poderia não tomar esta como uma das verdades indubitáveis." (WITTGENSTEIN, 1972, § 470). Outra passagem: "Por outro lado, no entanto, é certo dizer a mim mesmo "Eu não posso me enganar acerca de meu nome", e errado se eu digo "talvez eu esteja enganado". Mas isso não significa que é sem sentido que outros duvidem de uma convicção que eu declaro ter." (WITTGENSTEIN, 1972, § 629).

A ideia de Wolgast é de que qualquer certeza, confortável ou controversa, uma vez enunciada em um jogo de linguagem, está sujeita a revisões (está situada no mesmo nível dos demais enunciados). Ao ser 
enunciada, a proposição gramatical aparentemente empírica "Essa árvore existe", ainda que não tenha seu sentido questionado, já está comprometida com o caráter de certeza controversa por sua forma assertiva.

2) Wolgast compreende que as certezas que Wittgenstein afirma comporem nossa imagem de mundo estariam, na perspectiva do filósofo, como que "enterradas embaixo de nossa linguagem, no profundo de nossas vidas. Sua casa é um comportamento inarticulado e uma intimidade pré-linguística com as coisas" (WOLGAST, 1987, p. 159). Ela parece se remeter ao parágrafo 23 das Investigações, ao afirmar que Wittgenstein sugere que o sistema de convicções descrito por proposições gramaticais não é algo de ordem linguística, fazendo parte das atividades extralinguísticas que compõem uma forma de vida ${ }^{2}$. Tentemos compreender o que Wolgast quer dizer com isso.

Buscando ressaltar a dificuldade em que Wittgenstein se lança ao procurar enunciar determinadas regras conferindo a elas o estatuto de indubitáveis, Wolgast cita a seção 501 do Sobre a Certeza: "Eu não estou cada vez mais perto de afirmar que, no fim, a lógica não pode ser descrita?". Nesta passagem, Wittgenstein parece retomar a concepção de lógica exposta na seção 56 da mesma obra: "tudo o que é descritivo com relação a jogos de linguagem é parte da lógica", porém, acrescenta que, em seu cerne ou em seus princípios fundamentais, a lógica não pode ser descrita. O que esse acréscimo sugere? Segundo Wolgast, essa é a justificação dada pelo filósofo para situar as certezas confortáveis num âmbito exterior à linguagem, no terreno das práticas que condicionam os jogos de linguagem. Em suma: para Wolgast, Wittgenstein estaria situando o cerne da semântica de nossa linguagem em um âmbito que não pode ser tomado como objeto de estudo, o âmbito das atividades extralinguísticas de uma forma de vida.

Diante desse quadro, Wolgast se pergunta por aquilo que garante que os demais falantes de um jogo de linguagem compartilhem dos pressupostos extralinguísticos do falante que, pretensamente, enuncia uma proposição gramatical. A forma de exposição desta crítica é curiosa:

2 "O termo "jogo de linguagem" deve aqui salientar que o falar da linguagem é uma parte de uma atividade ou de uma forma de vida." (WITTGENSTEIN, 1979, § 23). 
dado que Wittgenstein parece admitir que as certezas confortáveis estão "enterradas embaixo da linguagem", é muito cabível a formulação da seguinte dúvida: e se a cerimônia de enterro estiver vazia?

3) Wolgast não intenciona negar o possível uso significativo dos truísmos de Moore, conquanto estes sejam tomados como sentenças empíricas especiais que "podem ser vistas, mas que não têm nenhuma função" (WOLGAST, 1987, p. 164). Sua crítica é direcionada à explicação do significado dos truísmos por Wittgenstein, com sua tese de um sistema de convicções que pode ser expresso na forma de proposições gramaticais, as quais, por sua vez, funcionam como regras indubitáveis que condicionam nossas ações e juízos. Ao que parece, diz Wolgast, Wittgenstein confere a determinadas proposições o estatuto de entidades (WOLGAST, 1987, p. 161). A autora defende que uma coisa é afirmar que crenças moldam nossas vidas (shape our lives) e outra é afirmar que proposições o fazem. Não está claro para ela por que Wittgenstein assume que certas proposições influenciam no modo como agimos da mesma maneira que ocorre com exemplos, modelos, e mesmo, punições e recompensas. Nada está tacitamente admitido com relação à tese de que nós acreditamos em truísmos e que eles podem reger nossas práticas na forma de regras ou princípios.

Com esses ataques aos argumentos apresentados no Sobre a Certeza, Wolgast procura denunciar uma contradição em que Wittgenstein cairia no que diz respeito aos seus estabelecimentos nas Investigações Filosóficas em que afirma que palavras (e proposições, consequentemente) são como ferramentas, só possuindo significado quando articuladas dentro de certos contextos. Nas Investigações, diz Wolgast, o filósofo nos adverte reiteradamente para não considerarmos expressões linguísticas isoladamente dos contextos em que são usadas e, no entanto, no Sobre a Certeza, dedica páginas e páginas a fazer considerações acerca de proposições cujo sentido não pode ser obtido a partir do contexto em que são enunciadas. Ela finaliza seu trabalho dizendo: 
Wittgenstein poderia muito bem ter argumentado que tratar certezas confortáveis como proposições dotadas de algum significado profundo, como desempenhando um papel de peso, ainda que silencioso, em nossas vidas é um caso de pensamento mal direcionado - um exemplo da mosca batendo suas asas contra a saída vedada da garrafa de apanhar moscas. Neste caso, ele teria procedido de maneira consistente com o método e a argumentação das Investigações, estendendo sua visão da conexão íntima entre a linguagem e a prática da vida e, ainda, refreando iniciativas filosóficas de dizer algo de absoluto, destacado de qualquer contexto e não qualificado. São as Investigações que contém a chave da estranha certeza dos truísmos, e é a visão das Investigações que eu evoco para embasar meu argumento aqui exposto. Ironicamente, o que era preciso era uma chave que já estava nas próprias mãos de Wittgenstein, chave que era, além disso, uma ferramenta de sua própria lavra (WOLGAST, 1987, p. 165).

\section{Refutação à crítica}

Assim como, logo no início da seção anterior, expus o ponto central da crítica de Wolgast, exponho também, logo no início desta seção, o fio condutor de minha refutação à crítica em questão: minha hipótese é de que proposições gramaticais não são exclusividade da Filosofia e têm, efetivamente, um uso na linguagem corrente.

Compreendo que, para a demonstração dessa hipótese, todos os argumentos fundamentais da crítica de Wolgast têm de ser rebatidos. Buscando expor agora os problemas que a autora apresenta a Wittgenstein em suas linhas mestras, identifico três questões, as quais procuro formular sinteticamente da seguinte maneira:

a) Há realmente distinção entre proposições gramaticais e proposições empíricas?;

b) Wittgenstein não entra em contradição consigo mesmo (com sua concepção de significado) ao assumir que o sistema de convicções descrito pelas proposições gramaticais é de caráter extralinguístico?;

c) Por que admitir que proposições gramaticais possuem evidentemente um uso em nossa linguagem e, ainda, que toda a nossa linguagem se apoia no que é enunciado por esse tipo de proposição? 
As duas primeiras objeções, defendo, são levantadas porque Wolgast não leva em conta o modo como o conceito de imagem (Bild) está relacionado à ideia da descritibilidade de um sistema de convicções. Quando Wittgenstein afirma que, em seu cerne, a lógica não pode ser descrita, ele não está necessariamente apelando para entidades extralinguísticas da maneira como sugere Wolgast.

Penso que uma das passagens fundamentais para que se entenda o conceito de imagem no Sobre a Certeza pode ser encontrado na segunda parte das Investigações Filosóficas - sintomaticamente, ambos os escritos datam de períodos muito próximos. Refiro-me ao seguinte trecho da seção VII da parte II das Investigações:

A evolução dos animais superiores e do homem e o despertar da consciência num determinado estágio. A imagem é mais ou menos esta: o mundo, apesar de todas as vibrações do éter que o atravessam, é escuro. Um dia, porém, o homem abre seus olhos que vêem, e torna-se claro.

Nossa linguagem descreve primeiramente uma imagem. O que deve acontecer com ela, como deve ser empregada, isto permanece nas trevas. Mas é claro que deve ser pesquisado, se quer compreender o sentido de nossas afirmações. A imagem, porém, parece dispensar-nos dessa tarefa; ela já indica um determinado emprego. Com isso, ela nos logra (WITTGENSTEIN, 1979, parte II, p.181).

O máximo de conhecimento que podemos obter, diz Wittgenstein, uma vez que chegamos à rocha dura (hartem Gestein) da linguagem, é uma descrição na forma de imagem. A imagem nos dispensa de elucidar o que se passa em nós, de procurar dentro de nós mesmos um objeto mental que possamos denominar "consciência". A expressão "Ela nos logra" significa: todos os integrantes do jogo de linguagem aceitam a imagem como evidência indubitável do que se passa em nós. É também uma imagem que nos contenta ao dizermos popularmente que a cegueira é como uma escuridão na alma ou na cabeça do cego (WITTGENSTEIN, 1979, § 424) e, filosoficamente, que "beleza, morte, etc., são substâncias puras (concentradas), enquanto que, em um objeto belo, elas estão contidas na forma de uma mistura" (WITTGENSTEIN, 1993, § 93 (S.434), p.199). O conceito "imagem" (Bild), conforme utilizado em certas passagens das Investigações e em escritos como Philosophy, entra em acordo com a ideia de uma imagem de mundo (Weltbild) que compõe a mitologia dos jogos de linguagem, conforme apresentado no Sobre a Certeza. Ao que 
tudo indica, uma imagem de mundo compartilhada por uma comunidade linguística é permeada por imagens como as apresentadas acima, na medida em que elas podem exibir o caráter indubitável próprio das regras que devem compor a base de nossa linguagem. Contudo, não devemos pensar que Wittgenstein afirma que a tarefa filosófica de descrever um jogo de linguagem nos remete a metáforas ou a analogias que reconhecemos como sendo meramente ilustrativas. Wittgenstein adverte: "somos conscientes de usar apenas uma imagem? Certamente que não. - Não é uma imagem de nossa escolha, não é uma metáfora, mas sim uma expressão figurada" (WITTGENSTEIN, 1979, parte II, p. 177). A diferença entre "metáfora" e "expressão figurada" parece ser de que nós podemos duvidar da imagem sugerida pela primeira, mas não podemos fazê-lo com relação à última.

A ideia de que uma imagem nos logra parece estar de acordo com a ideia de que a linguagem tem o poder de nos "enfeitiçar" o entendimento, de modo que a imagem, como regra, é seguida cegamente, sem uma demanda por qualquer elucidação (WITTGENSTEIN, 1979, § 109 e $\S 219$ ). Dessa forma, as imagens que compõem nossa imagem de mundo não são de caráter extralinguístico, são o limite do uso significativo da linguagem.

A título de exemplo, consideremos o contraste dos casos em que alguém ouve uma sentença em uma língua estranha e de alguém que ouve uma sentença em sua língua materna. O aspecto semântico das palavras, neste último caso, parece tomar, em grande parte, o lugar do aspecto fonético, de modo que é sumamente difícil para ele ouvir uma sentença em nossa língua materna destituindo das palavras ouvidas seu significado. Perguntar a esse falante o que, nos fonemas ouvidos, carrega o significado ou em que momento os sons passam a fazer sentido, é semelhante a pedir que alguém aponte quais os aspectos determinados que o levam a compreender e empregar uma imagem como sendo uma descrição de fatos.

No que diz respeito à terceira objeção (c), exposta com a formulação "Por que admitir que proposições gramaticais possuem evidentemente um uso em nossa linguagem?", é preciso admitir que, caso a enunciação de proposições gramaticais caiba unicamente à atividade filosófica, temos, efetivamente, um problema. Como explicar que alguém possa ter sido adestrado em determinadas técnicas de composição de proposições gramaticais se tais proposições não fazem parte da linguagem corrente? E, consequentemente: se não se pode falar de um adestramento 
na composição de proposições gramaticais, por que assumir que proposições gramaticais expressam o que Wittgenstein, nas Investigações, afirma ser o pressuposto para diversos usos de nossa linguagem - aquilo que já deve estar preparado na linguagem (in der Sprache vorbereitet sein (WITTGENSTEIN, 1979, § 31 e § 257)) como regra - ao invés de assumir que não há uso algum para essas proposições?

A solução que apresento é a denúncia de que estamos deixando de levar em conta, como fez Wolgast, uma advertência fundamental feita por Wittgenstein quanto à natureza das proposições gramaticais: trata-se da fluidez com que uma proposição pode se deslocar do posto de proposição indubitável (gramatical) que assume em um jogo de linguagem para um posto de proposição dubitável (empírica) em outros jogos de linguagem. Segundo Wittgenstein, não há algo como um conjunto de proposições que sempre desempenhe a função de "rocha dura" de todos os jogos de linguagem existentes em uma comunidade linguística: "A mitologia pode voltar a assumir um estado de fluxo, o leito do rio dos pensamentos pode se alterar. Mas eu traço uma diferença entre o movimento das águas no leito do rio e a alteração do fundo propriamente; embora não haja uma divisão nítida entre um e outro" (WITTGENSTEIN, 1972, § 97).

Proposições como "aqui estão duas mãos" ou "a água ferve a $100^{\circ} \mathrm{C}$ " nem sempre devem ser tomadas como a enunciação filosófica de pressupostos evidentes em todo e qualquer jogo de linguagem. É muito comum que crianças, no jardim de infância, aprendam a linguagem a partir de ensinamentos ostensivos nos quais são repetidos os nomes de partes do corpo humano. O jovem aprende na aula de Física o que, mais tarde, será um pressuposto compartilhado por todos os seus companheiros de trabalho, digamos, na indústria siderúrgica. A relação entre proposições empíricas e gramaticais se altera com o tempo. Proposições "fluidas" endurecem e proposições rígidas se fluidificam (WITTGENSTEIN, 1972, $\S 96$ ). A mesma proposição pode ser tratada, dependendo do contexto, como algo a ser testado pela experiência ou como uma regra de testagem (WITTGENSTEIN, 1972, § 98).

\section{CONCLUSÃO}

Espero ter demonstrado satisfatoriamente que as objeções de Wolgast são construídas sobre uma desconsideração da relação de 
complementaridade que há entre a concepção wittgensteiniana de significado - que versa que "a significação de uma palavra é seu uso na linguagem" (WITTGENSTEIN, 1979, § 43) - e a ideia de que os usos correntes da linguagem se apoiam em um sistema de convicções ou imagem de mundo passível de ser descrito por proposições gramaticais.

Explorando o conceito de imagem em Wittgenstein, e as funções que ele identifica como sendo desempenhadas por imagens na linguagem ordinária, procurei deixar claro que, se assumirmos que o que nos permite enunciar tais imagens é um uso gramatical ou mitológico da linguagem, a distinção entre proposições gramaticais e empíricas torna-se evidente, bem como o fato de que o sistema de convicções descrito pelas proposições gramaticais não é de caráter extralinguístico. Enfatizando a força do argumento da fluidez das proposições gramaticais apresentado em Sobre a Certeza, procurei demonstrar que proposições gramaticais possuem evidentemente um uso em nossa linguagem e, ainda, que não há problemas em assumir que nossa linguagem se apoia, efetivamente, no que é enunciado por esse tipo de proposição. Defender que aquilo que uma proposição gramatical descreve tem um caráter de regra fundamental em determinado jogo de linguagem nada mais é do que afirmar, por exemplo, que em um jogo de linguagem ambientado ao redor de uma mesa, num dado momento em que um dos falantes se levanta para pegar café, é o pressuposto de que este falante anteriormente já aprendeu que café é uma bebida preta de aroma peculiar que leva um segundo falante a enunciar o pedido "Traga um café para mim, por favor" sem antes precisar enunciar a proposição "Café é essa bebida preta de aroma peculiar". Dessa maneira, penso ter exposto adequadamente a hipótese de que proposições gramaticais não são exclusividade da Filosofia e têm, efetivamente, uso na linguagem corrente.

\section{REFERÊNCIAS}

KENNY, A. Wittgenstein. London: Penguin Books, 1973.

KOBER, M. Certainties of a world-picture: the epistemological investigations of On Certainty. In: SLUGA, H.; STERN, D. G. The cambridge companion to Wittgenstein. Edited by H. Sluga and D. Stern. Cambridge: Cambridge University Press, 1996. p. 411-441. 
WOLGAST, E. Whether certainty is a form of life. The Philosophical Quarterly, v. 37, n. 147, p. 151-165, 1987.

WITTGENSTEIN, L. On certainty. Translated by Denis Paul and G. E. Anscombe. New York: Harper \& Row, 1972.

Investigações filosóficas. Tradução de José Carlos Bruni. São Paulo: Abril Cultural, 1979. (Coleção Os pensadores).

. Philosophische untersuchungen. Frankfurt: Suhrkamp, 1984.

Philosophy. In: KLAGGE, J. C.; NORDMANN, A. Philosophical occasions 1912-1951. Indiana: Hackett Publishing Company, 1993.

Recebido: 10/12/2008

Received: 12/10/2008

Aprovado: 04/03/2009

Approved: 03/04/2009 